\title{
Free vibration analysis of thin circular plates by the indirect Trefftz method
}

\author{
A. Ghannadi-Asl ${ }^{1}$ \& A. Noorzad ${ }^{2}$ \\ ${ }^{1}$ Sama Organization (Affiliated with Islamic Azad University) - \\ Ardabil Branch, Iran \\ ${ }^{2}$ School of Civil Engineering, University of Tehran, Iran
}

\begin{abstract}
The vibration of plates is important in many applications pertaining to mechanical, civil and aerospace engineering. Therefore, the vibration of plates is an important research area that has been studied by many researchers. To date, there are abundant plate vibration solutions available in the open literature based on Kirchhoff assumptions. The purpose of the present paper is free vibration analysis of thin circular plates by the indirect Trefftz method. In thin plate vibration problems, we will deal with the governing equation with the homogeneous boundary conditions. The Trefftz method basically employs the complete set of solutions satisfying the governing equation as the first step. To derive the boundary integral equation, either the reciprocity law, which is similar to those used in conventional BEMs, or the weight residual method can be used. The proposed approach has some merits when compared with other regular boundary element formulations reported so far. A main benefit for the Trefftz method is that it does not involve singular integrals due to the properties of its solution basis functions ( $\mathrm{T}$ functions); thus, it can be categorized into the regular boundary element method. Besides, this advocated approach yields a solution that offers simultaneously the advantages of the classical FEM and BEM solutions, without having their drawbacks. Finally, several numerical examples are demonstrated to show the validity of the current approach.
\end{abstract}

Keywords: indirect Trefftz method, boundary-type solution, free vibration, thin circular plates. 


\section{Introduction}

Plates with various boundary conditions are common components in many fields of engineering, especially in civil and mechanical engineering. With the wide application of plate structures, static and dynamic analyses of plates become very important. We consider various kinds of motion of plates. There is a free vibration, which occurs in the absence of applied loads but may be initiated by applying initial conditions to the plate. The free vibration deals with natural characteristics of the plates, and these natural vibrations occur at discrete frequencies, depending only on the geometry and material of the plates. Then, there is a forced vibration, which results from an application of time-dependent loads. Forced vibrations come in two kinds: a harmonic response, when a periodic force is applied to the plate; and a transient response, when the applied force is not a periodic force. The dynamic characteristics of the plate have a considerable effect on the overall structure performance. When the frequency of the external load matches the natural frequency of the plate, damage or destruction may occur. With this respect, the natural frequencies of the plates have been studied extensively for more than a century. Therefore, vibration of the plate is an important research area that has been studied by many researchers.

For the solution of a free-vibration problem, many well-developed numerical techniques such as the finite element method (FEM), finite difference method (FDM) and boundary element method (BEM) can be adopted. This paper is concerned with the free vibration analysis of thin circular plates by using of the indirect Trefftz boundary approach [1]. In the indirect formulation, the solutions of the problems to be solved are approximated by the superposition of the $\mathrm{T}$ complete functions. Then, the unknown parameters are determined so that the approximate solutions satisfy the boundary conditions. Although in recent years various boundary solution methods have been applied to the thick plate bending problem [2-4], in the present work, we will restrict ourselves to the indirect Trefftz boundary approach and extend the method to free vibration analysis of thin circular plate problems.

Basically, the Trefftz method consists in the solution of a partial differential equation by the superposition of a number of functions, themselves solutions of the homogeneous governing equation, appropriately scaled by a number of unknown parameters. These unknowns are then obtained from the approximate satisfaction of the boundary conditions by means of collocation or in a weighted residual sense. Trefftz-based formulations have been studied by several authors, such as Jirousek and co-workers (of which Jirousek and Wrobleski [5] give a thorough account), Cheung et al. [6], Jin et al. [7], Zielinski and Zienkiewicz [8], Zielinski and Herrera [9], and Freitas and Ji [10] amongst others. Reviews on the subject may be found in Zielinski [11], Kita and Kamiya [12] and Jirousek and Wrobleski [5].

This paper is organized as follows. In section 2, the basic equations based on the Kirchhoff plate theory is explained in detail. Then, in section 3, the complete solutions and complete sets are shown. In section 4, the indirect Trefftz method is explained and in section 5, some numerical examples are shown to illustrate 
the efficiency of the Trefftz method. Finally, in section 6, the conclusions are drawn, briefly.

\section{Fundamental equations of classical plate theory}

Consider a circular plate of thin uniform thickness (h) with isotropic material and radius a. The classical differential equation of motion for the transverse displacement $\mathrm{w}$ of a plate is given by [13]:

$$
\mathrm{D} \nabla^{4} \mathrm{w}+\rho \mathrm{h} \frac{\partial^{2} \mathrm{w}}{\partial^{2} \mathrm{t}}=0
$$

where $\mathrm{D}=\mathrm{Eh}^{3} / 12\left(1-v^{2}\right)$ is known as the flexural rigidity of the plate and $\mathrm{E}$ is Young's modulus, $h$ is the plate thickness, $v$ is Poisson's ratio, $\rho$ is mass density of the plate material, $\mathrm{t}$ is time, and $\nabla^{4}=\nabla^{2} \cdot \nabla^{2}$, where $\nabla^{2}$ is the Laplacian operator. When free vibrations are assumed, the motion is expressed as

$$
\mathrm{w}_{\mathrm{i}}(\mathrm{r}, \theta, \mathrm{t})=\mathrm{W}^{(\mathrm{i})}(\mathrm{r}, \theta) \cos \left(\omega_{\mathrm{i}} \mathrm{t}\right)
$$

where $\omega_{i}$ is the natural frequency (expressed in radians/unit time) and $\mathrm{W}^{(\mathrm{i})}(\mathrm{r}, \theta)$ is its associated mode shape and a function only of the position coordinates. Substituting eqn. (2) into eqn. (1) yields

$$
\left(\nabla^{4}-\frac{\rho h \omega_{\mathrm{i}}^{2}}{\mathrm{D}}\right) \cdot \mathrm{W}^{(\mathrm{i})}(\mathrm{r}, \theta)=0
$$

It is usually convenient to factor eqn. (3) into

$$
\left(\nabla^{2}+\omega_{i} \sqrt{\frac{\rho h}{D}}\right) \cdot\left(\nabla^{2}-\omega_{i} \sqrt{\frac{\rho h}{D}}\right) \cdot W^{(i)}=0
$$

Whence, by the theory of linear differential equations, the complete solution to eqn. (4) can be obtained by superimposing the solutions to the equations:

$$
\begin{aligned}
& \nabla^{2} \mathrm{~W}_{1}^{(\mathrm{i})}+\mathrm{k}_{\mathrm{i}}^{2} \mathrm{~W}_{1}^{(\mathrm{i})}=0 \\
& \nabla^{2} \mathrm{~W}_{2}^{(\mathrm{i})}-\mathrm{k}_{\mathrm{i}}^{2} \mathrm{~W}_{2}^{(\mathrm{i})}=0
\end{aligned}
$$

where $k_{i}^{2}=\omega_{i} \sqrt{\frac{\rho h}{D}}$. Thus, the general solution to eqn. (4) in polar coordinates is:

$$
\mathrm{W}^{(\mathrm{i})}=\mathrm{W}_{1}^{(\mathrm{i})}+\mathrm{W}_{2}^{(\mathrm{i})}
$$


Based on Hooke's law and Kirchhoff's assumptions, the bending and twisting moment-displacement relations are given by [13]:

$$
\begin{aligned}
& M_{r}=-D \cdot\left[\frac{\partial^{2} \mathrm{w}}{\partial \mathrm{r}^{2}}+\frac{v}{\mathrm{r}} \frac{\partial \mathrm{w}}{\partial \mathrm{r}}+\frac{v}{\mathrm{r}^{2}} \frac{\partial^{2} \mathrm{w}}{\partial \theta^{2}}\right] \\
& \mathrm{M}_{\theta}=-\mathrm{D} \cdot\left[v \frac{\partial^{2} \mathrm{w}}{\partial \mathrm{r}^{2}}+\frac{1}{\mathrm{r}} \frac{\partial \mathrm{w}}{\partial \mathrm{r}}+\frac{1}{\mathrm{r}^{2}} \frac{\partial^{2} \mathrm{w}}{\partial \theta^{2}}\right] \\
& \mathrm{M}_{\mathrm{r} \theta}=-\mathrm{D} \cdot(1-\mathrm{v}) \frac{1}{\mathrm{r}} \frac{\partial}{\partial \theta}\left(\frac{\partial \mathrm{w}}{\partial \mathrm{r}}-\frac{\mathrm{w}}{\mathrm{r}}\right)
\end{aligned}
$$

Based on Kirchhoff plate theory, the shear forces-displacement relation can be obtained as:

$$
\begin{aligned}
& \mathrm{Q}_{\mathrm{r}}=-\mathrm{D} \frac{\partial}{\partial \mathrm{r}}\left[\frac{\partial^{2} \mathrm{w}}{\partial \mathrm{r}^{2}}+\frac{1}{\mathrm{r}} \frac{\partial \mathrm{w}}{\partial \mathrm{r}}+\frac{1}{\mathrm{r}^{2}} \frac{\partial^{2} \mathrm{w}}{\partial \theta^{2}}\right] \\
& \mathrm{Q}_{\theta}=-\mathrm{D} \frac{1}{\mathrm{r}} \frac{\partial}{\partial \theta}\left[\frac{\partial^{2} \mathrm{w}}{\partial \mathrm{r}^{2}}+\frac{1}{\mathrm{r}} \frac{\partial \mathrm{w}}{\partial \mathrm{r}}+\frac{1}{\mathrm{r}^{2}} \frac{\partial^{2} \mathrm{w}}{\partial \theta^{2}}\right]
\end{aligned}
$$

Based on Kirchhoff plate theory, equivalent change of slopes of the normal and tangential about the midsurface is given as follow:

$$
\begin{gathered}
\phi_{\mathrm{r}}=-\frac{\partial \mathrm{w}}{\partial \mathrm{r}} \\
\phi_{\theta}=\frac{\partial \mathrm{w}}{\partial \theta}
\end{gathered}
$$

\section{Complete solutions and complete sets}

Trefftz methods can be considered as the boundary-type solution procedure employing the regular T-complete functions satisfying the governing equations. Therefore, the input data generation is much easier than the domain-type solution procedures such as the finite element and the finite difference methods. Moreover, the formulations are regular and thus, much simpler than the ordinary boundary element methods employing the singular fundamental solutions. The complete solutions and complete sets corresponding to the governing equations (5) and (6) are used as weighting and/or trial functions. In the case of polar coordinates, the T-complete solution of the homogeneous equation of the biharmonic eqn. (5) can be found using separation of variables [14]: 


$$
\mathrm{W}_{1}^{(\mathrm{i})}=\sum_{\mathrm{n}=0}^{\infty}\left[\mathrm{a}_{\mathrm{n}} \mathrm{J}_{\mathrm{n}}\left(\mathrm{k}_{\mathrm{i}} \mathrm{r}\right)+\mathrm{b}_{\mathrm{n}} \mathrm{Y}_{\mathrm{n}}\left(\mathrm{k}_{\mathrm{i}} \mathrm{r}\right)\right] \cdot \operatorname{Cos}(\mathrm{n} \theta)+\left[\mathrm{c}_{\mathrm{n}} \mathrm{J}_{\mathrm{n}}\left(\mathrm{k}_{\mathrm{i}} \mathrm{r}\right)+\mathrm{d}_{\mathrm{n}} \mathrm{Y}_{\mathrm{n}}\left(\mathrm{k}_{\mathrm{i}} \mathrm{r}\right)\right] \cdot \operatorname{Sin}(\mathrm{n} \theta)
$$

The T-complete solution of the eqn. (6) can be found using separation of variables [14]:

$$
\mathrm{W}_{2}^{(\mathrm{i})}=\sum_{\mathrm{n}=0}^{\infty}\left[\mathrm{a}_{\mathrm{n}} \mathrm{I}_{\mathrm{n}}\left(\mathrm{k}_{\mathrm{i}} \mathrm{r}\right)+\mathrm{b}_{\mathrm{n}} \mathrm{K}_{\mathrm{n}}\left(\mathrm{k}_{\mathrm{i}} \mathrm{r}\right)\right] \cdot \operatorname{Cos}(\mathrm{n} \theta)+\left[\mathrm{c}_{\mathrm{n}} \mathrm{I}_{\mathrm{n}}\left(\mathrm{k}_{\mathrm{i}} \mathrm{r}\right)+\mathrm{d}_{\mathrm{n}} \mathrm{K}_{\mathrm{n}}\left(\mathrm{k}_{\mathrm{i}} \mathrm{r}\right)\right] \cdot \operatorname{Sin}(\mathrm{n} \theta)
$$

where $r$ is the Euclidean distance from the origin to a domain point, and $\theta$ is the angle between the $\mathrm{x}$-axis and the radial vector from the origin to the domain point. The special functions used in the expressions from eqn. (15) are Bessel functions of the first kind $\left(\mathrm{J}_{\mathrm{n}}\left(\mathrm{k}_{\mathrm{i}} \mathrm{r}\right)\right)$ and the second kind $\left(\mathrm{Y}_{\mathrm{n}}\left(\mathrm{k}_{\mathrm{i}} \mathrm{r}\right)\right)$. Also, the special functions used in the expressions from eqn. (16) are modified Bessel functions of the first kind $\left(\mathrm{I}_{\mathrm{n}}\left(\mathrm{k}_{\mathrm{i}} \mathrm{r}\right)\right)$ and the second kind $\left(\mathrm{K}_{\mathrm{n}}\left(\mathrm{k}_{\mathrm{i}} \mathrm{r}\right)\right)$. The coefficients of Bessel functions in equations (15) and (16) determine the mode shape and are solved for from the boundary conditions.

If the boundary conditions possess symmetry with respect to one or more diameters of the circle, then the terms involving $\sin (n \theta)$ are not needed. For solid circular plates, the terms involving $\mathrm{Y}_{\mathrm{n}}\left(\mathrm{k}_{\mathrm{i}} \mathrm{r}\right)$ and $\mathrm{K}_{\mathrm{n}}\left(\mathrm{k}_{\mathrm{i}} \mathrm{r}\right)$ in equations (15) and (16) must be discarded in order to avoid singularity of deflections and stresses (i.e., avoid infinite values) at the plate centre, $r=0$. Then, the $T$ complete sets of solutions for interior domain problem $(0 \leq \mathrm{r} \leq \mathrm{a})$ are as follows:

$$
\mathbf{B}_{w}=\left[J_{n}\left(k_{i} r\right) \operatorname{Cos}(n \theta), J_{n}\left(k_{i} r\right) \operatorname{Sin}(n \theta), I_{n}\left(k_{i} r\right) \operatorname{Cos}(n \theta), I_{n}\left(k_{i} r\right) \operatorname{Sin}(n \theta)\right] n=0,1,2, \ldots
$$

\section{Indirect Trefftz formulation}

The indirect formulation, considered as the original formulation presented by Trefftz in 1926, the solution of the problem is approximated by the superposition of the functions satisfying the governing equation and then, the unknown parameters are determined so that the approximate solution satisfies the boundary condition by means of the collocation, the least square or the Galerkin method [12]. In this approach, the trial functions are expanded in terms of a sequence of linearly independent Trefftz functions and a discrete set of unknown coefficients a. However, the weighting functions may be chosen in different ways. When the Dirac delta function is used, the method leads to the Trefftz collocation method (TCM). If the Trefftz function is employed as the weight function, the method leads to the Trefftz Galerkin method (TGM) [15]. To illustrate the weighted residual procedure [16], we shall consider the 
determination of a function (u), which may be a quantity within a region $\Omega$ bounded, by $\Gamma$, defined by the general equation:

$$
\mathrm{L}(\mathrm{u})=0 \quad \text { in } \Omega
$$

subject to the boundary conditions:

$$
\begin{array}{llll}
\mathrm{w}-\overline{\mathrm{w}}=0 & \phi_{\mathrm{s}}-\bar{\phi}_{\mathrm{s}}=0 & \phi_{\mathrm{n}}-\bar{\phi}_{\mathrm{n}}=0 & \text { on } \Gamma_{\mathrm{c}} \\
\mathrm{w}-\overline{\mathrm{w}}=0 & \phi_{\mathrm{s}}-\bar{\phi}_{\mathrm{s}}=0 & \mathrm{M}_{\mathrm{n}}-\overline{\mathrm{M}}_{\mathrm{n}}=0 & \text { on } \Gamma_{\mathrm{s}} \\
\mathrm{Q}_{\mathrm{n}}-\overline{\mathrm{Q}}_{\mathrm{n}}=0 & \mathrm{M}_{\mathrm{ns}}-\overline{\mathrm{M}}_{\mathrm{ns}}=0 & \mathrm{M}_{\mathrm{n}}-\overline{\mathrm{M}}_{\mathrm{n}}=0 & \text { on } \Gamma_{\mathrm{f}}
\end{array}
$$

These conditions are obtained from natural boundary and $\Gamma_{\mathrm{c}}, \Gamma_{\mathrm{s}}$ and $\Gamma_{\mathrm{f}}$ stand for clamped, simply supported and free boundary conditions for which the displacement is specified, and the quantities $(\boldsymbol{\bullet})$ stands for specified boundary values. The operator L may be either differential or integral operator and is also either linear or nonlinear in nature. If $\mathrm{u}^{0}$ is some approximation to you then equations (17) and (18) will not be satisfied exactly. Let us assume that errors involved are:

$$
\begin{array}{lll}
\mathrm{L}\left(\mathrm{u}^{0}\right)=\mathrm{E}_{1} & \\
\mathrm{w}\left(\mathrm{u}^{0}\right)-\overline{\mathrm{w}}=\mathrm{E}_{2} \quad, & \phi_{\mathrm{s}}\left(\mathrm{u}^{0}\right)-\bar{\phi}_{\mathrm{s}}=\mathrm{E}_{3} \quad, \quad \phi_{\mathrm{n}}\left(\mathrm{u}^{0}\right)-\bar{\phi}_{\mathrm{n}}=\mathrm{E}_{4} \\
\mathrm{M}_{\mathrm{n}}\left(\mathrm{u}^{0}\right)-\overline{\mathrm{M}}_{\mathrm{n}}=\mathrm{E}_{5} \quad, \quad \mathrm{M}_{\mathrm{ns}}\left(\mathrm{u}^{0}\right)-\overline{\mathrm{M}}_{\mathrm{ns}}=\mathrm{E}_{6} \quad, \quad \mathrm{Q}_{\mathrm{n}}\left(\mathrm{u}^{0}\right)-\overline{\mathrm{Q}}_{\mathrm{n}}=\mathrm{E}_{7}
\end{array}
$$

where $E_{1}-E_{7}$ are residual error functions. To determine the approximate solution of $\mathrm{u}^{0}$ some weighted integral of errors, defined in eqn. (19), is set to zero, so that:

$$
\begin{aligned}
& \int_{\Omega} \mathrm{w}_{1}^{*}\left(\mathrm{~L}\left(\mathrm{u}^{0}\right)\right) \cdot \mathrm{d} \Omega+\int_{\Gamma_{\mathrm{w}}} \mathrm{w}_{2}^{*}\left(\mathrm{w}^{0}-\overline{\mathrm{w}}\right) \cdot \mathrm{d} \Gamma+\int_{\Gamma_{\phi_{\mathrm{s}}}} \mathrm{w}_{3}^{*}\left(\phi_{\mathrm{s}}{ }^{0}-\bar{\phi}_{\mathrm{s}}\right) \cdot \mathrm{d} \Gamma+\int_{\Gamma_{\phi_{\mathrm{n}}}} \mathrm{w}_{4}^{*}\left(\phi_{\mathrm{n}}{ }^{0}-\bar{\phi}_{\mathrm{n}}\right) \cdot \mathrm{d} \Gamma \\
& +\int_{\Gamma_{\mathrm{M}_{\mathrm{n}}}} \mathrm{w}_{5}^{*}\left(\mathrm{M}_{\mathrm{n}}{ }^{0}-\overline{\mathrm{M}}_{\mathrm{n}}\right) \cdot \mathrm{d} \Gamma+\int_{\Gamma_{\mathrm{M}_{\mathrm{s}}}} \mathrm{w}_{6}^{*}\left(\mathrm{M}_{\mathrm{ns}}{ }^{0}-\overline{\mathrm{M}}_{\mathrm{ns}}\right) \cdot \mathrm{d} \Gamma+\int_{\Gamma_{\mathrm{M}_{\mathrm{ns}}}} \mathrm{w}_{7}^{*}\left(\mathrm{Q}_{\mathrm{n}}{ }^{0}-\overline{\mathrm{Q}}_{\mathrm{n}}\right) \cdot \mathrm{d} \Gamma=0
\end{aligned}
$$

where $\mathrm{w}_{\mathrm{i}}^{*}(\mathrm{i}=1-7)$ are a set of independent weighting functions and in this case, the operator $\mathrm{L}$ is defined as follow:

$$
\begin{aligned}
& \mathrm{L}(\mathrm{u})=\nabla^{2} \mathrm{~W}_{1}^{(\mathrm{i})}+\mathrm{k}_{\mathrm{i}}^{2} \mathrm{~W}_{1}^{(\mathrm{i})} \\
& \mathrm{L}(\mathrm{u})=\nabla^{2} \mathrm{~W}_{2}^{(\mathrm{i})}-\mathrm{k}_{\mathrm{i}}^{2} \mathrm{~W}_{2}^{(\mathrm{i})}
\end{aligned}
$$

Now suppose that the approximate solution of the generalized displacements $\mathrm{W}_{1}^{(\mathrm{i})}$ and $\mathrm{W}_{2}^{(\mathrm{i})}$ can be expressed by a series as: 


$$
\begin{aligned}
& \mathrm{W}_{1}^{(\mathrm{i})}=\sum \mathrm{N}_{\mathrm{W}_{1}^{(\mathrm{i})}} \mathrm{a}_{\mathrm{j}} \\
& \mathrm{W}_{2}^{(\mathrm{i})}=\sum \mathrm{N}_{\mathrm{W}_{2}^{(\mathrm{i})}} \mathrm{a}_{\mathrm{j}}
\end{aligned}
$$

where $\mathrm{a}_{\mathrm{j}}$ are undetermined coefficients, $\mathrm{N}_{\mathrm{W}_{1}^{(i)}}$ and $\mathrm{N}_{\mathrm{W}_{2}^{(i)}}$ are the complete sets of Trefftz functions. $\mathrm{N}_{\mathrm{W}_{1}^{(i)}}$ and $\mathrm{N}_{\mathrm{W}_{2}^{(i)}}$ are chosen such that they satisfy a priori the homogeneous equations in equations (5) and (6), i.e. for any function $\mathrm{N}_{\mathrm{W}_{1}^{(i)}}$ and $\mathrm{N}_{\mathrm{W}_{2}^{(i)}}$, we have:

$$
\begin{aligned}
& \nabla^{2} \mathrm{~N}_{\mathrm{W}_{1}^{(\mathrm{i})}}+\mathrm{k}_{\mathrm{i}}^{2} \mathrm{~N}_{\mathrm{W}_{1}^{(\mathrm{i})}}=0 \\
& \nabla^{2} \mathrm{~N}_{\mathrm{W}_{2}^{(\mathrm{i})}}-\mathrm{k}_{\mathrm{i}}^{2} \mathrm{~N}_{\mathrm{W}_{2}^{(\mathrm{i})}}=0
\end{aligned}
$$

Substituting equations (25) and (26) into equations (8)-(14) and transforming the polar co-ordinate system to the local co-ordinate system $(\mathrm{n}, \mathrm{s})$, the variables in eqn. (20) can be written as:

$$
\begin{array}{lll}
\mathrm{w}^{0}=\sum \mathrm{N}_{1 \mathrm{i}} \mathrm{a}_{\mathrm{i}}=\mathbf{N}_{1} \mathbf{a} & , & \phi_{\mathrm{s}}{ }^{0}=\sum \mathrm{N}_{2 \mathrm{i}} \mathrm{a}_{\mathrm{i}}=\mathbf{N}_{2} \mathbf{a} \\
\phi_{\mathrm{n}}{ }^{0}=\sum \mathrm{N}_{3 \mathrm{i}} \mathrm{a}_{\mathrm{i}}=\mathbf{N}_{3} \mathbf{a} & , & \mathrm{M}_{\mathrm{n}}{ }^{0}=\sum \mathrm{N}_{4 \mathrm{i}} \mathrm{a}_{\mathrm{i}}=\mathbf{N}_{4} \mathbf{a} \\
\mathrm{M}_{\mathrm{ns}}{ }^{0}=\sum \mathrm{N}_{5 \mathrm{i}} \mathrm{a}_{\mathrm{i}}=\mathbf{N}_{5} \mathbf{a} & , & \mathrm{Q}_{\mathrm{n}}{ }^{0}=\sum \mathrm{N}_{6 \mathrm{i}} \mathrm{a}_{\mathrm{i}}=\mathbf{N}_{6} \mathbf{a}
\end{array}
$$

where $\mathbf{a}$ is undetermined coefficients, $\mathbf{N}_{\mathbf{i}}(\mathrm{i}=1-6)$ is the complete sets of Trefftz functions. In the Galerkin method, the Trefftz functions are also used as the weighting functions such that $[17,18]$ :

$$
\begin{array}{llll}
\mathrm{w}_{1}^{*}=\mathrm{N}_{1}, & \mathrm{w}_{2}^{*}=\mathrm{N}_{6 \mathrm{j}}, \quad \mathrm{w}_{3}^{*}=-\mathrm{N}_{5 \mathrm{j}} \\
\mathrm{w}_{4}^{*}=-\mathrm{N}_{4 \mathrm{j}}, & \mathrm{w}_{5}^{*}=\mathrm{N}_{3 \mathrm{j}}, \quad, \quad \mathrm{w}_{6}^{*}=\mathrm{N}_{2 \mathrm{j}}, \quad \mathrm{w}_{7}^{*}=-\mathrm{N}_{1 \mathrm{j}}
\end{array}
$$

where functions $\mathrm{N}_{\mathrm{ij}}(\mathrm{i}=1-6, \mathrm{j}=1,2,3, .$.$) can be obtained by introducing the \mathrm{T}$ complete functions into equations (8)-(14). Substituting equations (27) and (28) into eqn. (20), we obtain the jth equation of the system of linear equations in the following discrete form:

$$
\begin{aligned}
& \int_{\Gamma_{\mathrm{w}}} \mathrm{N}_{6 \mathrm{j}}\left(\mathrm{N}_{1 \mathrm{i}}-\overline{\mathrm{w}}\right) \cdot \mathrm{d} \Gamma-\int_{\Gamma_{\phi \mathrm{s}}} \mathrm{N}_{5 \mathrm{j}}\left(\mathrm{N}_{2 \mathrm{i}}-\bar{\phi}_{\mathrm{s}}\right) \cdot \mathrm{d} \Gamma-\int_{\Gamma_{\phi \mathrm{n}}} \mathrm{N}_{4 \mathrm{j}}\left(\mathrm{N}_{3 \mathrm{i}}-\bar{\phi}_{\mathrm{n}}\right) \cdot \mathrm{d} \Gamma \\
& +\int_{\Gamma_{\mathrm{M}_{\mathrm{n}}}} \mathrm{N}_{3 \mathrm{j}}\left(\mathrm{N}_{4 \mathrm{i}}-\overline{\mathrm{M}}_{\mathrm{n}}\right) \cdot \mathrm{d} \Gamma+\int_{\Gamma_{\mathrm{M}_{\mathrm{ns}}}} \mathrm{N}_{2 \mathrm{j}}\left(\mathrm{N}_{5 \mathrm{i}}-\overline{\mathrm{M}}_{\mathrm{ns}}\right) \cdot \mathrm{d} \Gamma-\int_{\Gamma_{\mathrm{Qn}_{\mathrm{n}}}} \mathrm{N}_{1 \mathrm{j}}\left(\mathrm{N}_{6 \mathrm{i}}-\overline{\mathrm{Q}}_{\mathrm{n}}\right) \cdot \mathrm{d} \Gamma=0
\end{aligned}
$$


The domain integral term in eqn. (29) can be transformed into a boundary integral by using Green's second identity. The matrix equation for the solution of the problem is

$$
\mathbf{K a}=\mathbf{f}
$$

where

$$
\begin{aligned}
\mathbf{K}= & \int_{\Gamma_{\mathrm{w}}} \mathrm{N}_{6 \mathrm{j}} \mathrm{N}_{1 \mathrm{i}} \cdot \mathrm{d} \Gamma-\int_{\Gamma_{\phi_{\mathrm{s}}}} \mathrm{N}_{5 \mathrm{j}} \mathrm{N}_{2 \mathrm{i}} \cdot \mathrm{d} \Gamma-\int_{\Gamma_{\phi_{\mathrm{n}}}} \mathrm{N}_{4 \mathrm{j}} \mathrm{N}_{3 \mathrm{i}} \cdot \mathrm{d} \Gamma+\int_{\Gamma_{\mathrm{M}_{\mathrm{n}}}} \mathrm{N}_{3 \mathrm{j}} \mathrm{N}_{4 \mathrm{i}} \cdot \mathrm{d} \Gamma \\
& +\int_{\Gamma_{\mathrm{M}_{\mathrm{ns}}}} \mathrm{N}_{2 \mathrm{j}} \mathrm{N}_{5 \mathrm{i}} \cdot \mathrm{d} \Gamma \quad-\int_{\Gamma_{\mathrm{Qn}}} \mathrm{N}_{1 \mathrm{j}} \mathrm{N}_{6 \mathrm{i}} \cdot \mathrm{d} \Gamma
\end{aligned}
$$

and

$$
\begin{aligned}
\mathbf{f}= & \int_{\Gamma_{\mathrm{w}}} \mathrm{N}_{6 \mathrm{j}} \overline{\mathrm{W}} \cdot \mathrm{d} \Gamma-\int_{\Gamma_{\phi_{\mathrm{s}}}} \mathrm{N}_{5 \mathrm{j}} \bar{\phi}_{\mathrm{s}} \cdot \mathrm{d} \Gamma-\int_{\Gamma_{\phi_{\mathrm{n}}}} \mathrm{N}_{4 \mathrm{j}} \bar{\phi}_{\mathrm{n}} \cdot \mathrm{d} \Gamma+\int_{\Gamma_{\mathrm{M}_{\mathrm{n}}}} \mathrm{N}_{3 \mathrm{j}} \overline{\mathrm{M}}_{\mathrm{n}} \cdot \mathrm{d} \Gamma \\
& +\int_{\Gamma_{\mathrm{M}_{\mathrm{ns}}}} \mathrm{N}_{2 \mathrm{j}} \overline{\mathrm{M}}_{\mathrm{ns}} \cdot \mathrm{d} \Gamma-\int_{\Gamma_{\mathrm{Qn}}} \mathrm{N}_{1 \mathrm{j}} \overline{\mathrm{Q}}_{\mathrm{n}} \cdot \mathrm{d} \Gamma
\end{aligned}
$$

The resulting matrix $\mathrm{K}$ is full. The unknown generalized parameters $\boldsymbol{a}$ can be determined from eqn. (30) using Gaussian elimination method with row pivots. Substituting the determined coefficients a back into series (27), we can obtain any quantity that we need either inside the domain or on the boundary.

\section{Numerical examples}

Two simple examples are presented to illustrate the use of the indirect Trefftz method and the accuracy of the numerical results. The solutions have been obtained by using the Trefftz Galerkin Method (TGM). The boundary variables include constant, linear and quadratic interpolations. For simplicity, $v=0.3$ and $\mathrm{D}=1$ have been used in the following examples.

\subsection{Example 1: clamped circular plate all round}

In the present example, a clamped circular plate is considered and frequency parameters are obtained. Owing to the presence of a smooth boundary, continuous elements have been adopted. Values of frequency parameter $\left(\lambda^{2}=\omega \mathrm{a}^{2} \sqrt{\frac{\rho h}{\mathrm{D}}}\right)$ found using indirect Trefftz method are tabulated in Table 1, where $\mathrm{n}$ and $\mathrm{s}$ refer to the number of radial and circumferential nodes, respectively. Inspection of table 1 shows that, the frequency parameters obtained using this method is in good agreement. Table 1 shows the convergence of the 


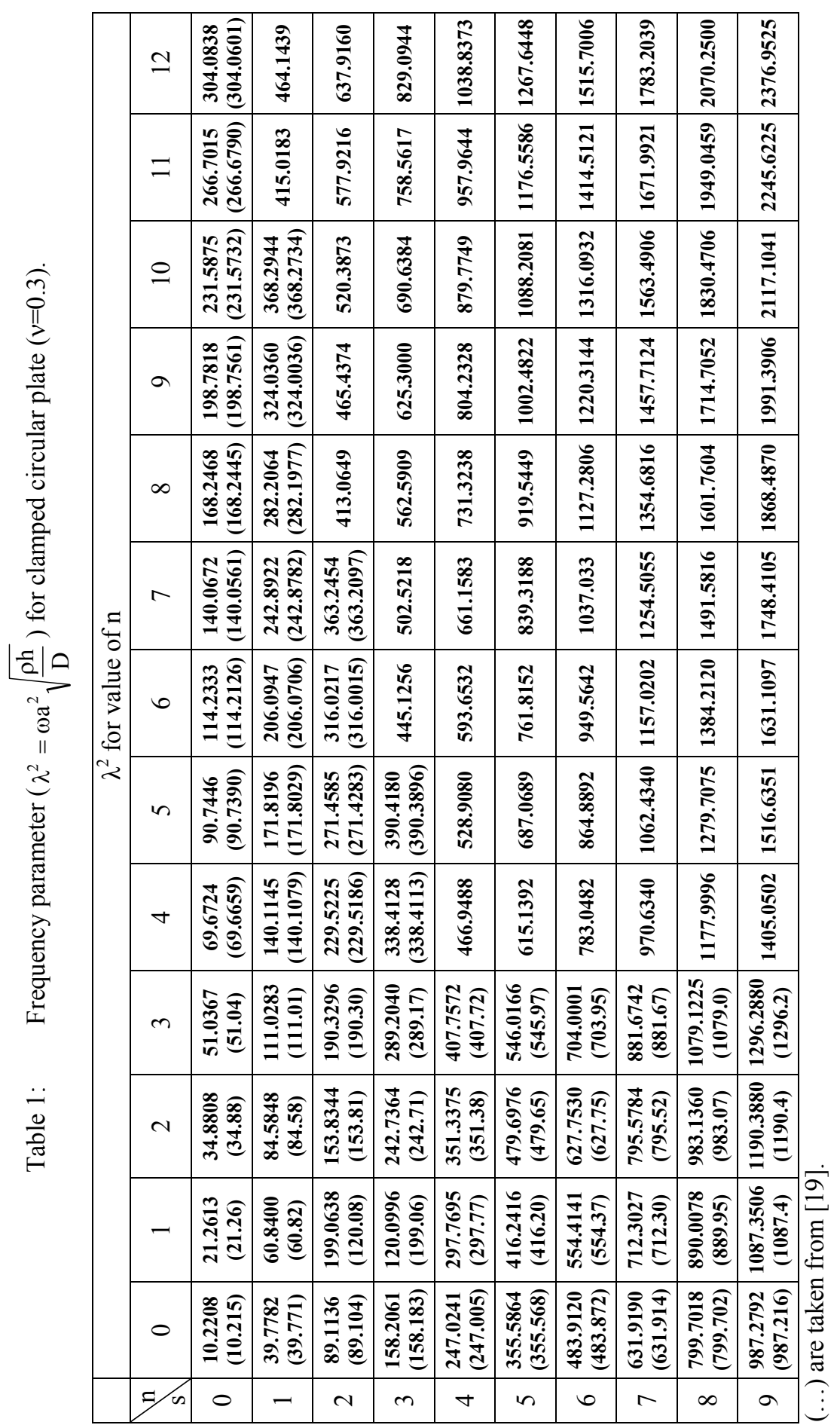




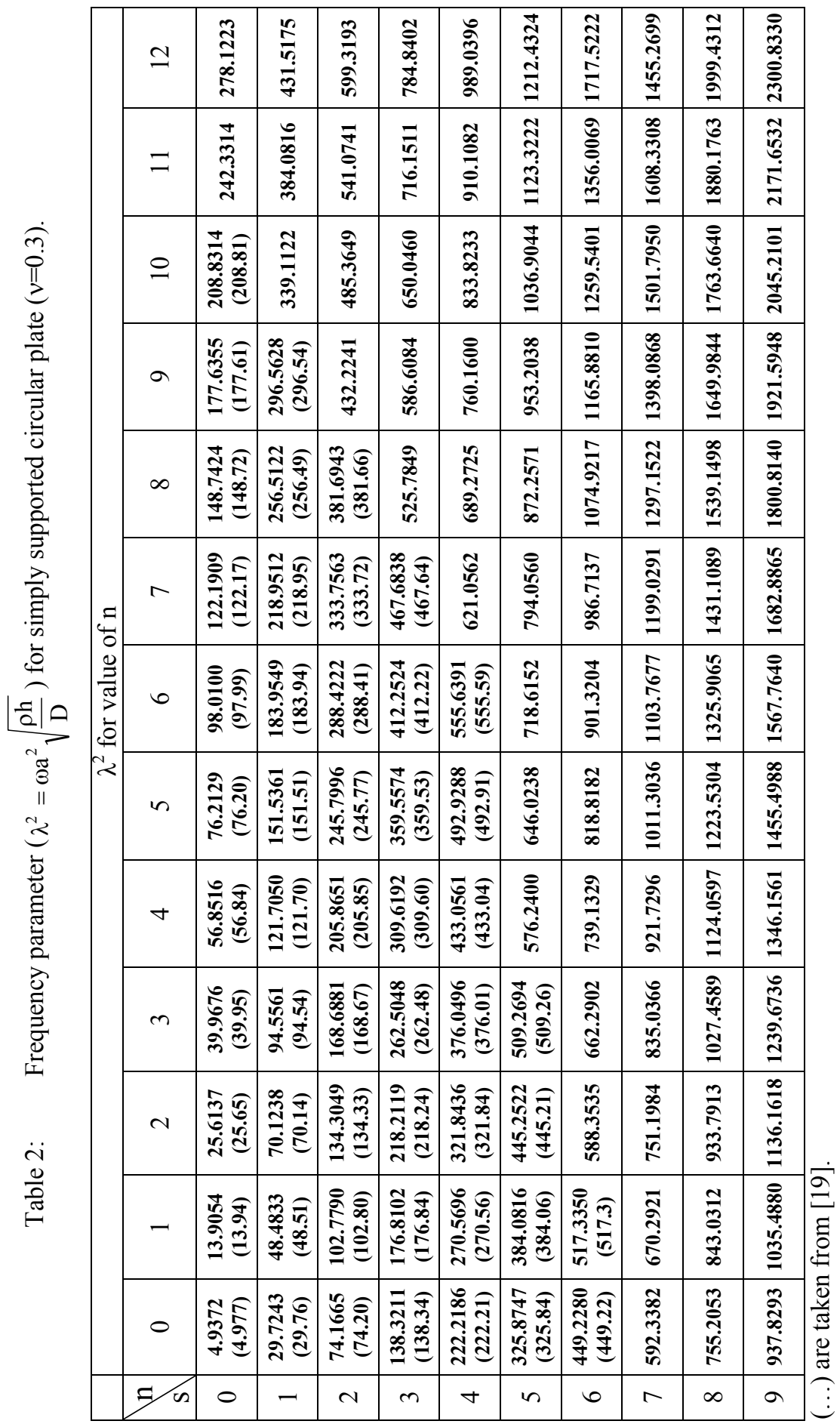


natural frequencies with the number of out-of-plane shape functions. The values are compared with the ones published by Leissa [19]. For the fundamental frequency, this method gives acceptable results with a maximum discrepancy of $0.03 \%$ clamped boundary conditions.

\subsection{Example 2: simply supported circular plate all round}

A simply supported circular plate with uniform thicknesses is taken as an example. The corresponding discretisation and the number of elements can be similarly adopted as example 1. Values of frequency parameter found using indirect Trefftz method are tabulated in table 2. For the fundamental frequency, this method gives acceptable results with a maximum discrepancy of $0.01 \%$ simply supported boundary conditions. It can be seen that, by comparison with the Leissa's results [19], the present method is able to give satisfactory results.

\section{Conclusions}

The purpose of the present paper is free vibration analysis of thin circular plates by indirect Trefftz method. In thin plate vibration problems, we will deal with the governing equation with the homogeneous boundary conditions. The Trefftz methods can be classified into the indirect and direct formulations. Most of the researchers have been studying the indirect formulations. In this article, indirect formulation has been applied to thin plate vibration problems. The main conclusions of this paper can be summarized as follows:

1. The indirect Trefftz formulation is very similar to the direct boundary element formulation.

2. The computational accuracy of the indirect Trefftz method is strongly dependent on the condition numbers of the coefficient matrices.

3. Although the examples are relatively simple, we may say that numerical solutions prove that the present method is not only effective but also provides accurate numerical results.

\section{References}

[1] Trefftz, E., Ein gegenstuck zum ritzschen verfharen, In Proc. 2nd Int. Cong. Appl. Mech., pp. 131-137, 1926.

[2] Weeeën, F. V., Application of the boundary integral equation method to Reissner's plate model, Int. J. Numer. Meth. Engng., 18, pp. 1-10, 1982.

[3] Weeeën, F. V., Application of the direct boundary element method to Reissner's plate model, in Boundary Element Method in Engineering, C. A. Brebbia (ed.), Springer, Berlin, pp. 487-499, 1982.

[4] Lei, X. Y. \& Hung, M. K., Mixed method of BIEM \& FEM to solve free vibration of Reissner's plate, in Boundary Elements, Q. H. Du (ed.), Pergamon Press, Oxford, 1986.

[5] Jirousek, J. \& Wroblewski, A., T-elements: State of the art and future trends. Archives of Comp. Meth. in Engng, 3(4), pp. 323-434, 1996. 
[6] Cheung, YK., Jin, WG. \& Zienkiewicz, OC., Direct solution procedure for solution of harmonic problems using complete, non-singular, Trefftz functions. Com. Appl. Num. Meth., 5, pp. 159-169, 1989.

[7] Jin, W.G., Cheung, YK. \& Zienkiewicz, OC., Trefftz method for Kirchhoff plate bending problems. Int. J. Num. Meth. Eng., 36, pp. 765-781, 1993.

[8] Zielinski, AP. \& Zienkiewicz, OC., Generalized finite element analysis with t-complete boundary solution functions. Int. J. Num. Meth. Eng., 21, pp. 509-528, 1985.

[9] Zielinski, AP. \& Herrera, I., Trefftz method: fitting boundary conditions. Int. J. Num. Meth. Eng., 24, pp. 871-891, 1987.

[10] Freitas, J. \& Ji, Z., Hybrid-Trefftz finite element formulation for simulation of singular stress fields. Int. J. Num. Meth. Eng., 39, pp. 281-308, 1996.

[11] Zielinski, AP., On trial functions applied in the generalized Trefftz method. Advances in Engineering Software, 24, pp. 147-155, 1995.

[12] Kita, E. \& Kamiya, N., Trefftz method: an overview. Advances in Engineering Software, 24, pp. 3-12, 1995.

[13] Reismann, H., Elastic Plates: theory and Application, Wiley, New York, 1988.

[14] Finlayson, B.A., the Method of weighted Residuals and variational Principles, Academic Press, New York, 1972.

[15] Reddy, J.N., Energy Principles and Variational Methods in Applied Mechanics, McGraw-Hill, 2001.

[16] Banerjee, P.K., The boundary element Methods in Engineering, 2nd ed, McGraw-Hill, 1981.

[17] Hochard, Ch. \& Proslier, L., A simplified analysis of plate structures using Trefftz-functions, Int. J. Numer. Meth. Engng, 34, pp. 179-195, 1992.

[18] Portela, A. \& Charafi, A., Trefftz boundary element-multi region formulation, Int. J. Numer. Meth. Engng., 45, pp. 821-840, 1999.

[19] Leissa, A.W., Vibration of Plates, NASA SP.160, Washington, 1969. 